\title{
Impact of cholinesterase inhibitors on behavioral and psychological symptoms of Alzheimer's disease: A meta-analysis
}

\author{
Noll Campbell' \\ Amir Ayub² \\ Malaz A Boustani \\ Chris Fox ${ }^{3}$ \\ Martin Farlow ${ }^{4}$ \\ lan Maidment ${ }^{3}$ \\ Robert Howard ${ }^{5}$
}

'Wishard Health Services, Indianapolis, Indiana; ${ }^{2}$ Indiana University Center for Aging Research, Regenstrief Institute, Inc., Indianapolis, Indiana; ${ }^{3}$ University of Kent, Kent, United Kingdom; ${ }^{4}$ Indiana University School of Medicine, Indianapolis, Indiana; ${ }^{5}$ King's College, London, United Kingdom
Correspondence: Malaz A Boustani Regenstrief Institute, Inc., 410 West I0th Street, Suite 2000, Indianapolis, IN 46202-30I 2, USA

$\mathrm{Tel}+\mathrm{I} 3174265633$

Fax +I 3174235695

Email mboustani@regenstrief.org
Objective: To determine the efficacy of cholinesterase inhibitors (ChEIs) in improving the behavioral and psychological symptoms of dementia (BPSD) in patients with Alzheimer's disease (AD).

Data sources: We searched MEDLINE, Cochrane Registry, and the Cumulative Index to Nursing and Allied Health Literature (CINAHL) from 1966 to 2007. We limited our search to English Language, full text, published articles and human studies.

Data extraction: We included randomized, double-blind, placebo-controlled trials evaluating the efficacy of donepezil, rivastigmine, or galantamine in managing BPSD displayed by AD patients. Using the United States Preventive Services Task Force (USPSTF) guidelines, we critically appraised all studies and included only those with an attrition rate of less than $40 \%$, concealed measurement of the outcomes, and intention to treat analysis of the collected data. All data were imputed into pre-defined evidence based tables and were pooled using the Review Manager 4.2.1 software for data synthesis.

Results: We found 12 studies that met our inclusion criteria but only nine of them provided sufficient data for the meta-analysis. Among patients with mild to severe AD and in comparison to placebo, ChEIs as a class had a beneficial effects on reducing BPSD with a standard mean difference (SMD) of -0.10 (95\% confidence interval [CI]; $-0.18,-0.01)$ and a weighted mean difference (WMD) of -1.38 neuropsychiatry inventory point $(95 \% \mathrm{CI} ;-2.30,-0.46)$. In studies with mild AD patients, the WMD was -1.92 (95\% CI; $-3.18,-0.66)$; and in studies with severe AD patients, the WMD was -0.06 (95\% CI; $-2.12,+0.57)$.

Conclusion: Cholinesterase inhibitors lead to a statistical significant reduction in BPSD among patients with $\mathrm{AD}$, yet the clinical relevance of this effect remains unclear.

Keywords: Alzheimer's disease, dementia, cholinesterase inhibitors, behavioral and psychological symptoms

\section{Introduction}

The noncognitive behavioral and psychological symptoms of dementia (BPSD) displayed by patients suffering from Alzheimer disease (AD) include a heterogeneous spectrum of psychological reactions, psychiatric symptoms, and behaviors (Finkel et al 2000). More than $90 \%$ of AD patients will experience at least one BPSD at some point during the course of their illness (Tariot and Blazina 1994; Haupt et al 2000; Lyketsos et al 2000). A community-based epidemiological study found that $61 \%$ of AD patients exhibited one or more BPSD in the past month and $61 \%$ of those with no baseline BPSD developed at least one symptom within 18 months (Lyketsos et al 2000; Steinberg et al 2003). In a nursing home study a baseline prevalence of $76 \%$, a two-year prevalence of $82 \%$, and an annual incidence of $64 \%$ was detected (Ballard et al 2001). 
BPSD are a major problem for patients and their caregivers. They are considered one of the strongest predictors for institutionalization of demented patients (Colerick and George 1986; Steele et al 1990; O’Donnell et al 1992; Haupt and Kurz 1993; Teresi and Weiner 1993; Swearer 1994); a prominent risk factor for caregiver burden and psychological morbidity (Kinney and Stephens 1989; Hamel et al 1990; Haupt and Kurz 1993; Morris et al 1996); a significant obstacle in achieving adequate medical management for other health conditions (Cohen-Mansfield 1995; Brodaty et al 2001); and a common cause of stress leading to staff burnout and subsequent turnover in institutional settings (Maslach and Jackson 1981).

The traditional pharmacological management of BPSD has significant morbidity including extrapyramidal signs and symptoms, gait abnormalities, sedation, an increased risk of falls and fractures, incidence of delirium, cerebrovascular events, and death (Cummings 2000a; Cummings et al 2000, 2001; Boustani et al 2002). An agent specific for AD that can treat BPSD with fewer side effects is highly desirable. Currently ChEIs are the standard of care for the treatment of cognitive deficit in patients with AD (Doody et al 2001; Boustani et al 2002). Compared to alternatives, they are considered to have a more acceptable side effect profile (Boustani et al 2002). Over the past decade, their potential role as psychotropic agents has been investigated in a variety of basic and clinical studies, which have suggested that the central cholinergic deficit associated with AD may be causative for the cognitive deterioration and the neuropsychiatric manifestations of AD (Kaufer et al 1998; Cummings 2000a, 2000b; Cummings et al 2001; Chung and Cummings 2000). Previously, evaluating the use of ChEIs in managing BPSD has been reported in a meta-analysis by Trinh and colleagues (2003) which included published trials of ChEIs up to 2001. Trinh included patients with mild-moderate AD only and included studies which used metrifonate, which is no longer available for the treatment of AD. However, since the publication of Trinh meta-analysis, numerous new trials have been published that investigated further the role of ChEIs as a psychotherapeutic agent in AD. The aim of our study was to systematically review the available literature and examine the therapeutic role of the currently available ChEIs in decreasing the burden of BPSD among patients with any stage of AD living in any clinical setting.

\section{Methods}

\section{Search strategies}

We searched MEDLINE from 1966 to 2007, Cochrane Collaboration Registry for Randomized Controlled Trials (RCT) from 1966 to 2007 and CINAHL from
1982 to 2007, using the following search terms: Alzheimer's disease, dementia, donepezil, rivastigmine, galantamine, cholinesterase inhibitors and behavioral and psychological symptoms. We limited our search to the English language, full text, published articles and human studies. We also retrieved relevant references of included studies for our search.

\section{Selection criteria}

The main goal of our systematic evidence review (SER) was to evaluate the efficacy of the currently available ChEIs in treating BPSD in patients with AD. Thus, we included only RCTs that evaluated the efficacy of any of the three FDA-approved and commonly used ChEIs (donepezil, rivastigmine, galantamine). We also included only studies that measured the BPSD with the Neuropsychiatric Inventory (NPI) among patients with any stage of AD living in any clinical setting. We selected NPI as the main outcome measure because it is considered by many investigators as the standard method to measure BPSD. The NPI is an informant-based structured interview with acceptable psychometric properties (Cummings et al 1994; Cummings and Kaufer 1996; Wood et al 2000; Schneider et al 2001). Higher scores indicate higher frequency and severity of BPSD and a positive change from baseline reflects worsening symptoms (Cummings et al 1994). We excluded pre and post studies and randomized controlled trials involving patients other than AD. Studies which were not placebo-controlled were also excluded from our SER.

\section{Critical appraisal}

Using the USPSTF critical appraisal method for quality assessment, we critically appraised the studies and included those with an attrition rate of less than $40 \%$, a concealed measurement of the outcomes, and intention to treat analysis of the collected data.

\section{Data abstraction}

Three reviewers (AA, MB, NC) independently searched for the articles and abstracted data from each study that met our inclusion criteria into predefined evidence tables, that included: citation, total number of randomized patients, baseline demographic data (age, gender, educational level), mean Mini-Mental Status Examination score (MMSE), setting, duration of studies, drug used in studies, attrition rate, mean total NPI score, mean change from baseline of the total NPI score for both the treatment and placebo groups, and the level of significance for the mean difference in NPI between the two groups. 


\section{Quantitative data synthesis}

We used Review Manager Software Version 4.2.1 (http:// www.cc-ims.net/RevMan; Plone Foundation, Houston, TX, USA) to calculate the effect size and confidence interval (CI) of each individual study and the combined results. The effect size is the difference in the change of the total NPI score from baseline between the treatment and the placebo groups divided by the pooled standard deviation. In addition, we were also interested in identifying any potential confounder for the effect of ChEIs on BPSD such as disease stage and specific drug. Thus, we conducted a series of sensitivity analyses that combined data from the studies using similar inclusion criteria and interventions. Authors were also contacted for the data not reported or missing in the studies. After testing the heterogeneity of included trials, we primarily used a random effect model to combine the results of included studies. Other factors which were considered when carrying out the meta- analysis were sources of variation, such as sample sizes, dosing regimens, differences between treatment durations and routes of administration. Confounding variables would be MMSE scores or stage of symptom and age of the patients. Variations such as these would impact effect sizes, but as long as these effect sizes are in the same direction, whether negative or positive, a reliable effect would be evident.

\section{Results}

\section{Review flow}

Our search strategies yield a total of 105 potentially relevant RCTs for retrieval. sixteen studies were excluded as they were not placebo-controlled trials and 27 studies were further excluded as they were open label, subgroup analyses or duplicate studies. Out of remaining 62 studies, 50 studies were excluded as they failed to meet the inclusion criteria. Finally, 12 randomized controlled trials (RCTs) met the inclusion criteria for our SER (see Tables 1 and 2) and only nine studies provided complete data to conduct the meta-analysis.

\section{Study characteristics}

As demonstrated in Tables 1 and 2, the included studies were conducted among a heterogeneous group of participants with mild to severe cognitive deficits with a mean MMSE score ranging from 6.1 to 21 . The mean difference of the primary outcome measure was not reported in three studies, which were therefore excluded from the meta-analysis. Five studies were conducted in outpatient settings, two in nursing homes, four in community and residential settings together, and one study did not report the clinical setting. Nine studies compared donepezil, two compared galantamine and one compared rivastigmine with placebos. The length of the studies varied from 3 to 12 months. The target dose of donepezil was $10 \mathrm{mg}$ per day; that of galantamine varied from 16 to $24 \mathrm{mg}$ daily; and rivastigmine was administered as either a capsule or a skin patch with target doses of 3-12 $\mathrm{mg}$ and $20 \mathrm{~cm}^{2}$ patches per day, respectively.

The mean age of the participants ranged from 72.5 to 85.7 years and the percentage of female participants ranged

Table I Baseline variables of the included studies

\begin{tabular}{|c|c|c|c|c|c|c|}
\hline Study & $\mathbf{N}$ & Mean age & $\%$ Female & $\begin{array}{l}\text { Education } \\
\text { level (years) }\end{array}$ & Mean MMSE & Total NPI Score \\
\hline Tariot et al 2000 & 978 & 76 & 64 & NR & 18 & II.9 (I0 items) \\
\hline Feldman et al $200 \mathrm{I}$ & 290 & 73.6 & 61 & NR & 12 & 19.55 (I2 items) \\
\hline Rockwood et al $200 \mathrm{I}$ & 386 & 75 & 56.5 & NR & 20 & 9.20 (10 items) \\
\hline Tariot et al $200 \mathrm{I}$ & 208 & 85.7 & 82.5 & NR & 14 & $\begin{array}{l}21.0 \text { (I2 items) } \\
\text { NPI-NH }\end{array}$ \\
\hline Winblad et al 200I & 286 & 72.5 & 64 & NR & 19 & I 3.05 (I0 items) \\
\hline Gauthier et al 2002 & 207 & 74.3 & 65 & NR & 13.7 & I7.3 (12 items) \\
\hline Nunez et al 2003 & 202 & - & - & - & - & - \\
\hline AD2000 et al 2004 & 566 & - & 59 & NR & - & - \\
\hline Holmes et al 2004 & 96 & 80.9 & 60.5 & NR & 21 & 14.30 (10 items) \\
\hline Winblad et al 2006 & 248 & 84.9 & 76.5 & NR & 6.1 & 19.30 (I2 items) \\
\hline Winblad et al 2007 & 1195 & 73.6 & 66.5 & 9.9 & 16.5 & I4.75 (I 2 items) \\
\hline Howard et al 2007 & 259 & 84.6 & 84.5 & NR & 8.1 & 23.65 (I2 items) \\
\hline
\end{tabular}

Abbreviations: N, total number of subjects included in the study; NPI, neuropsychiatric Inventory; NPI-NH, neuropsychiatric inventory-nursing home; NR, not reported. 
from $56.5 \%$ to $84.5 \%$. Education level was reported in only one study and was 9.9 years. NPI was used as primary outcome measure in only two studies (Tariot et al 2001; Holmes et al 2004) and the secondary outcome measure in nine studies for the assessment of BPSD. The mean baseline NPI score ranged from 9.20 to 23.65. Two different versions of the NPI (10-item scale with score ranges from 0 to 120 points versus 12 -item scale with score ranges from 0 to 144) were used. Baseline total NPI score was higher in the five studies that evaluated moderate to severe $\operatorname{AD}(15.1,19.30,19.55,21.0$ and 23.65) in comparison to the four studies which evaluated mild to moderate $\operatorname{AD}(9.2,11.9,13.05,14.3)$.

\section{Quantitative data analyses}

The studies were not homogenous and therefore, we used the random effect model to combine their results and reported the standard mean difference (SMD). However, we have also reported the result from the fixed effect model and reported the weighted mean difference (WMD) for comparison with other reported meta-analyses (See Figure 1).

Table 2 Evidence table for all included studies

\begin{tabular}{|c|c|c|c|c|c|c|c|c|}
\hline Study & Countries & Setting & Drug & $\begin{array}{l}\text { Length } \\
\text { (months) }\end{array}$ & $\mathbf{N}$ & $\begin{array}{l}\text { Mean } \\
\text { difference }\end{array}$ & $\begin{array}{l}\text { Intervention } \\
\text { attrition } \\
\text { rate, \% }\end{array}$ & $\begin{array}{l}\text { Placebo } \\
\text { attrition } \\
\text { rate, } \%\end{array}$ \\
\hline Tariot et al 2000 & USA & Out-patient & Galantamine & 5 & 770 & $-2.10 \mathrm{SS}$ & 22 & 16 \\
\hline $\begin{array}{l}\text { Feldman et al } \\
200 \mathrm{I}\end{array}$ & $\begin{array}{l}\text { Canada, } \\
\text { Australia, } \\
\text { France }\end{array}$ & Out-patient & Donepezil & 6 & 290 & -5.65 SS & 16 & 14 \\
\hline $\begin{array}{l}\text { Rockwood et al } \\
200 \text { I }\end{array}$ & $\begin{array}{l}\text { USA, } \\
\text { Canada, } \\
\text { Britain, } \\
\text { South Africa, } \\
\text { Australia, } \\
\text { New Zealand }\end{array}$ & Out-patient & Galantamine & 3 & 386 & $-0.90 \mathrm{NS}$ & 33 & 10 \\
\hline Tariot et al 200I & USA & $\begin{array}{l}\text { Nursing } \\
\text { homes }\end{array}$ & Donepezil & 6 & 208 & $2.60 \mathrm{NS}$ & 18 & 26 \\
\hline $\begin{array}{l}\text { Winblad et al } \\
200 \mathrm{I}\end{array}$ & $\begin{array}{l}\text { Northern } \\
\text { European } \\
\text { countries }\end{array}$ & Out-patient & Donepezil & 12 & 286 & -1.13 NS & 33 & 33 \\
\hline $\begin{array}{l}\text { Gauthier et al } \\
2002\end{array}$ & $\begin{array}{l}\text { Canada, } \\
\text { Australia, } \\
\text { France, } \\
\text { USA }\end{array}$ & $\begin{array}{l}\text { Community/ } \\
\text { Residential }\end{array}$ & Donepezil & 6 & 207 & NR & 19 & II \\
\hline $\begin{array}{l}\text { Nunez et al } \\
2003\end{array}$ & $\begin{array}{l}\text { Finland, } \\
\text { Hungary, } \\
\text { Denmark. }\end{array}$ & NR & Donepezil & 6 & 202 & NR & NR & NR \\
\hline $\begin{array}{l}\text { AD2000 et al } \\
2004\end{array}$ & UK & $\begin{array}{l}\text { Community/ } \\
\text { Residential }\end{array}$ & Donepezil & 15 & 566 & NR & 11 & 5 \\
\hline $\begin{array}{l}\text { Holmes et al } \\
2004\end{array}$ & UK & Out-patient & Donepezil & 6 & 96 & $-6.2 \mathrm{SS}$ & 15 & 18 \\
\hline $\begin{array}{l}\text { Winblad et al } \\
2006\end{array}$ & Sweden & $\begin{array}{l}\text { Nursing } \\
\text { Homes }\end{array}$ & Donepezil & 6 & 248 & $-1.70 \mathrm{NS}$ & 26 & 18 \\
\hline $\begin{array}{l}\text { Winblad et al } \\
2007\end{array}$ & $\begin{array}{l}\text { Sweden, } \\
\text { USA, } \\
\text { Germany, } \\
\text { Switzerland }\end{array}$ & $\begin{array}{l}\text { Community/ } \\
\text { Residential }\end{array}$ & $\begin{array}{l}\text { Rivastigmine } \\
\text { (20 cm-patch) } \\
\text { (capsule) }\end{array}$ & 6 & 1078 & $\begin{array}{l}-0.60 \mathrm{NS} \\
-0.50 \mathrm{NS}\end{array}$ & $\begin{array}{l}20 \\
21\end{array}$ & 12 \\
\hline Howard et al 2007 & $\begin{array}{l}\text { United } \\
\text { Kingdom }\end{array}$ & $\begin{array}{l}\text { Residential/ } \\
\text { Community }\end{array}$ & Donepezil & 3 & 259 & $-0.22 \mathrm{NS}$ & 10 & 14 \\
\hline
\end{tabular}

Abbreviations: MD, mean difference of change on total NPI score between placebo and treatment; NR, not reported; NS, not significant; SS, statistically significant. Note: Negative values indicate greater improvement in symptoms in the active treatment group. 


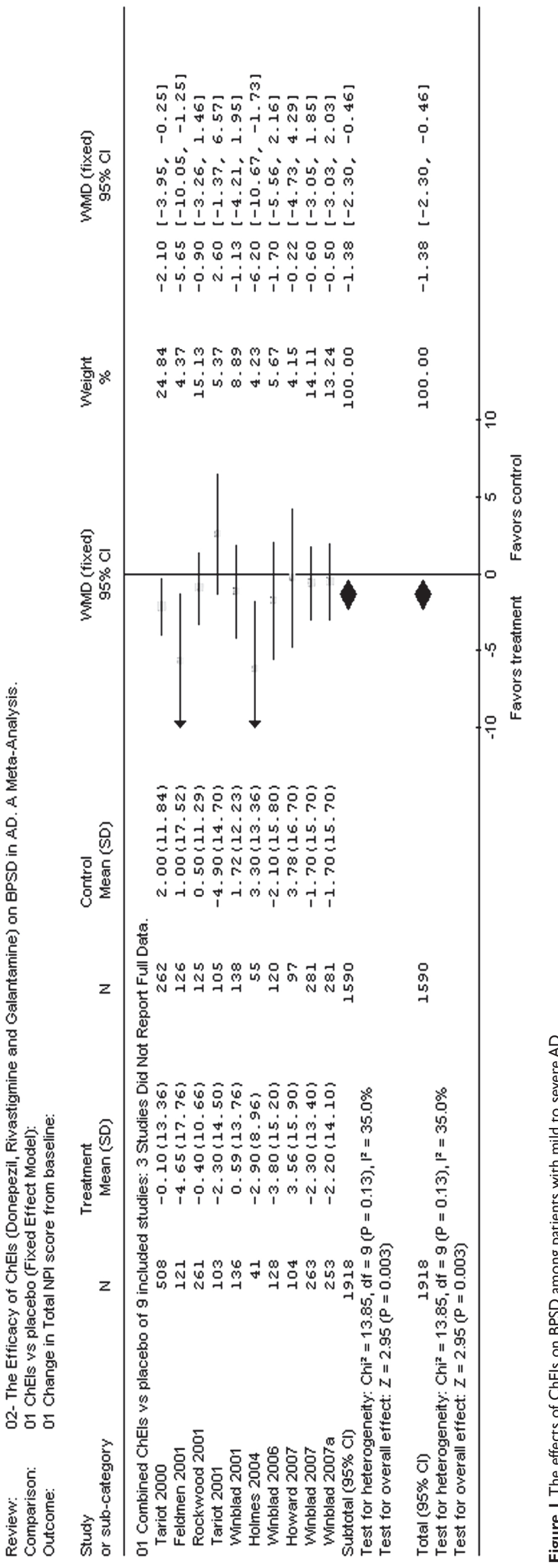

Patients receiving ChEIs (donepezil, rivastigmine or galantamine) improved the total NPI score when compared to the placebo with a SMD between the two groups of $-0.10(95 \% \mathrm{CI}:-0.18,-0.01)$ and a WMD of $-1.38(95 \% \mathrm{CI}:-2.20,-0.46)$. Combining only the results of homogenous studies, for example, those conducted among patients with mild-moderate AD showed that the SMD between the two groups was -0.16 (95\% CI: $-0.28,-0.03)$ and the WMD was -1.92 (95\% CI: $-3.18,-0.66$ ) (see Figure 2).

When results of studies that included patients with moderate-severe $\mathrm{AD}$ were evaluated, the impact of ChEIs was not statistically significant anymore with a SMD of -0.06 (95\% CI: $-0.17,0.05)$ and a WMD of $-0.77(95 \%$ CI: -2.12 , 0.57 ) (see Figure 3).

Looking at the effect of each of the three ChEIs separately, we found that the SMD between galantamine and placebo (two studies) was -1.65 (95\% CI: $-3.10,-0.19)$, between donepezil and placebo ( 6 studies) was -1.76 (95\% CI: $-3.37,-0.15)$ and between rivastigmine and placebo (one study) was -0.55 (95\% CI: $-2.31,1.21)$.

Data on the individual domains of the NPI was not available to conduct a meta-analysis, but two studies (Feldman et al 2001; Tariot et al 2001) reported that donepezil significantly improved depression/dysphoria and apathy, but only anxiety symptoms were improved in one trial and only agitation/aggression in the other.

\section{Discussion}

\section{Clinically relevant change} in BPSD as measured by NPI

Our meta-analysis found that in comparison to placebo, 3 to 12 months' treatment with ChEIs had positive effects on global BPSD scores with an effect size (SMD) of 0.10 and WMD of 1.38 NPI points. The challenge, however, is to determine the clinical significance of this effect size and whether such an effect can be translated into reducing patients' or caregivers' burden. Various clinical investigators have used different total NPI points to determine the clinical meaning of NPI total change score. Kaufer and colleagues (1998) decided that a reduction or improvement of at least $50 \%$ in the average baseline NPI scores, approximately nine points difference on the total NPI score, is considered a clinically relevant change. We compared our results to a similar study published by Trinh and colleagues (2003). This study evaluated the impact of ChEIs on behavioral symptoms in patients with mild-moderate $\mathrm{AD}$. The authors 


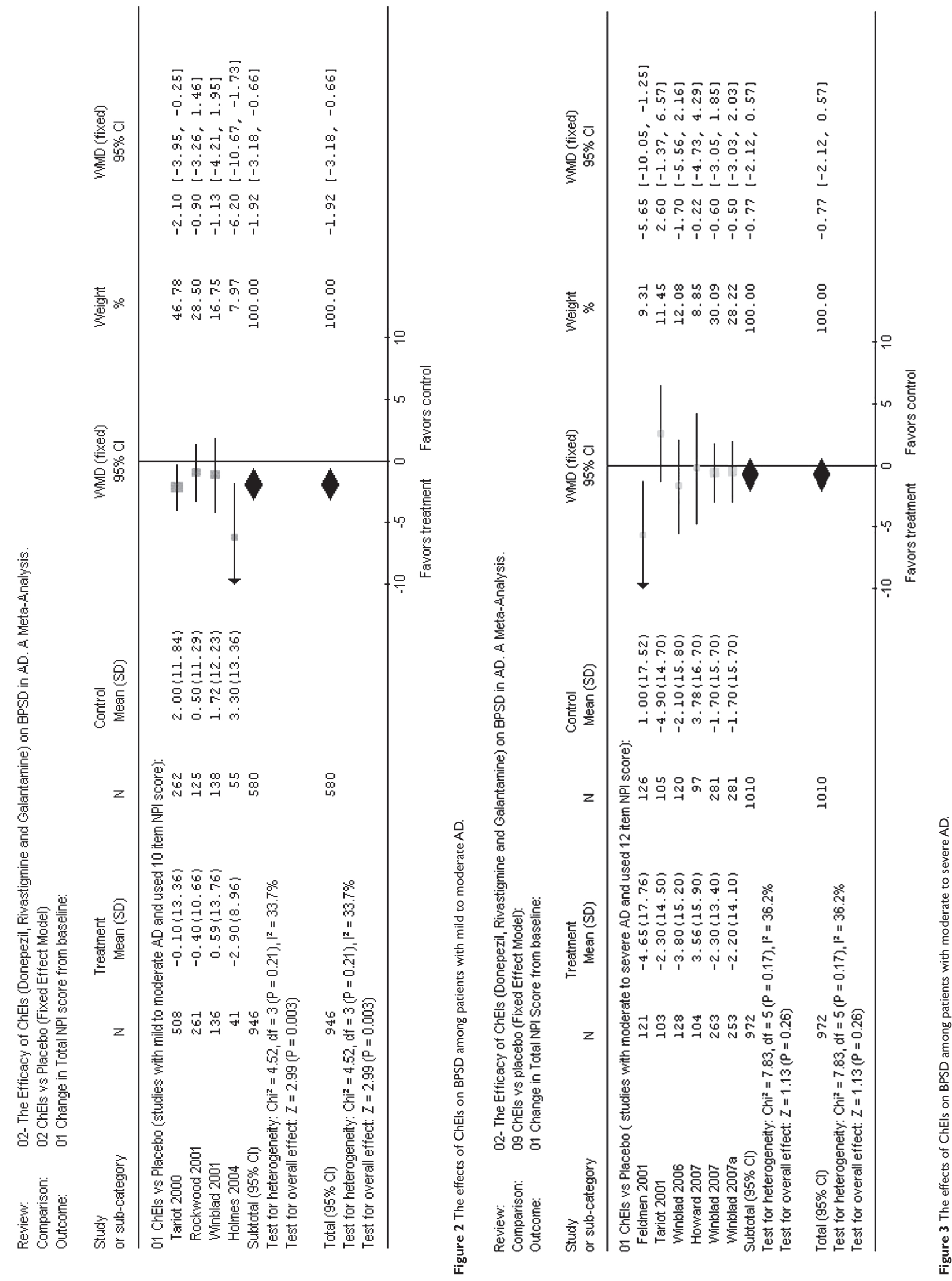


found a WMD in improvement in NPI scores between all ChEIs (including metrifonate) and placebo of 1.72 (95\% CI: 0.87-2.57). By comparison, our study found similar results as the Trinh study when results for a similar population were evaluated (WMD -1.92 for patients in a mild-moderate stage of dementia). However, our results suggest this difference in NPI scores does not extend to the moderate-severe population (WMD of -0.77 with $95 \%$ CI of -2.12 to +0.57 ). The efficacy of ChEIs (galantamine and rivastigmine) on BPSD in other types of dementia such as vascular dementia and Lowy body dementia has been evaluated in two other studies (Erkinjuntti et al 2002; McKeith et al 2002). Both controlled trials had similar results as our study with a difference in mean change from baseline between treatment and placebo group of 2.3 points on the total NPI score for the vascular dementia trial (baseline total NPI score $=11.8$ ) and 3.8 for trial including patients with Lewy body dementia (baseline total NPI score $=21.7$ ). To further compare the clinical significance of our meta-analysis, we looked at the results of trials that used the NPI to evaluate the efficacy of an atypical antipsychotic (olanzapine) in reducing BPSD among AD nursing home residents who had clinically significant levels of behavioral and psychological symptoms at baseline with a total NPI score of at least 44 points (Street et al 2000). In comparison to placebo, the mean decline from baseline in total NPI score was 8.3 points among patients taking olanzapine for six weeks (Street et al 2000). Although the ChEIs' trials did not specifically enroll patients with baseline behavioral and psychological symptoms, the difference in the NPI changes from baseline between olanzapine and placebo was much higher than what we detected in our meta-analysis.

\section{The natural history of the BPSD}

Before evaluating the efficacy of ChEIs on BPSD, one must examine their natural history as measured by a specific instrument such as the NPI. In a cross-sectional study, community dwelling elderly patients with dementia had a total NPI mean score of 7.11 $(\mathrm{SD}=10.9)$ as compared to $0.76(\mathrm{SD}=2.89)$ points of those with no dementia. In addition, the total score increased as dementia-related disability worsened, individuals with mild dementia had a mean total score on the NPI of $5.80(\mathrm{SD}=12.5)$, those with moderate dementia had a mean score of $8.8(\mathrm{SD}=11.10)$, and those with severe dementia had a mean score of 10.6 (SD = 17.0) (Lyketsos et al 2002). The mean total NPI score increased dramatically, ie, 36.4 $(\mathrm{SD}=24.5)$, among patients with moderate to severe dementia admitted to the hospital for the management of their disturbed behaviors (Iverson et al 2002). The prevalence data provide an idea of the total NPI score range but they do not explain the fluctuating nature of BPSD. During any specified period of time certain behaviors or symptoms will emerge, others will cease, some deteriorate, and others will improve (Levy et al 1996; Devanand et al 1997; Green et al 1999; Ballard et al 2001). This fluctuating pattern of BPSD must be accounted for when interpreting the efficacy of certain interventions. We are unaware of any study that tried to determine whether this fluctuating pattern occurred on daily, weekly, monthly, or yearly basis.

\section{Limitations}

Our study has some limitations. First, we restricted our review to BPSD measured by the NPI. We were concerned that including other measures would make it difficult to interpret the data. Nevertheless, the NPI is considered the current standard instrument to evaluate BPSD. We previously reviewed all RCTs of ChEIs that evaluated the efficacy of tacrine on BPSD and found similar results from trials using the Alzheimer's Disease Assessment Scale-Noncognitive symptoms (ADAS-noncog) (Cummings et al 2001). Secondly, we did not include individual domains of the NPI in our analysis, which may have truncated our findings. There is lack of published data on each of these 12 domains, although two included trials (Tariot et al 2000; Feldman et al 2001) reported the effect on individual domains but did not produce data that could be combined for meta-analysis (Tariot et al 2000; Feldman et al 2001). As the effect of ChEIs are likely to be greater on some BPSD than others, we believe that evaluating the effects of cholinesterase inhibitors on individual domains may carry more clinical meaning than using the global scale which sums all the BPSD in one score. The third limitation is related to being unable to identify the difference in the proportion of responders between placebo and treatment groups. One trial (Tariot et al 2001) with NPI as the primary outcome reported the difference in the percentage of patients who had worsening symptoms on the agitation domain (placebo 32\%, donepezil 24\%), but it only stated that no significant finding was detected in the other domains (Tariot et al 2001). We agree with Mulsant and colleagues (1997) in regard to the advantage of using comparisons based on the resolution of target BPSD domains or even the total score of NPI (categorical approach) rather than the use of an absolute or relative change in total score in interpreting the clinical value of certain interventions targeting BPSD. Finally, our review could not determine if the ChEI's effects were due to stability of BPSD among the treatment group 
versus deterioration among the placebo group, or if their effects reflected a true improvement in treatment groups.

\section{Research need}

Our review found a statistically significant effect of ChEIs (donepezil, rivastigmine, and galantamine) on BPSD in AD patients. However, we could not interpret the clinical relevance of this finding. Given the heterogeneity of BPSD and the need to explore further the efficacy of ChEIs in managing BPSD, we need to have a more clinically focused evaluation method. This method could be accomplished by either conducting a new clinical trial (a very expensive and ethically challenging method because ChEIs are considered to be the current standard of care in $\mathrm{AD}$ ) or a retrospective post-hoc analysis of individual data from the 12 clinical trials that we included in our meta-analysis. The analytic framework for the suggested study would stratify the participants into two groups based on their baseline NPI total score: the prevention strata; which would include individuals with low NPI scores $(\leq 20)$ and crisis intervention strata; which would include individuals with high NPI scores $(>20)$. Although the NPI would still be the main assessment tool, the trial would evaluate the impact of ChEIs using the individual domain scores for the NPI and a categorical approach to identify responders. The primary outcome would be the proportion of responders after 3 to 6 months. The responders would be defined differently between the two strata: in the prevention strata, the responders would include any individual with at least a stable NPI domain score at the end of the study, whereas in the crisis strata, the responders would include any individual who had at least a $30 \%$ reduction in their domain score. The study might also include additional data from the two trials that tested rivastigmine efficacy in dementia with Lewy body and galantamine efficacy in vascular dementia. Using this methodology (categorical outcome and changes in domain score) would enable us to report the difference in proportion of items improved, worsened, emerged, and/or ceased between treatment and control groups, and thus, we would better understand the clinical meaning of positive effects. A detailed investigation of the effect of ChEIs on specific behaviors at different stages of illness may be beneficial. We await the results of an acute phase BPSD study using memantine (MAGD ISRCTN24953404) and studies on new drugs such as tarenflurbil (Wilcock et al 2008). Specific medical, supportive, social or psychological interventions in agitation require further evidence.

\section{Conclusions}

Cholinesterase inhibitors (donepezil, rivastigmine, and galantamine) have consistently shown a statistically significant improvement on BPSD as measured by the NPI. However, the existing clinical relevance of these findings is unclear and the use of this class of medications for BPSD does not appear to produce the necessary effect to be considered as monotherapy of behavioral or psychological symptoms in patients with dementia.

\section{Disclosure}

The authors report no conflicts of interest in this work.

\section{References}

AD2000 Collaborative Group. 2004. Long-term donepezil treatment in 565 patients with Alzheimer's disease (AD2000): randomized double-blind trial. Lancet, 363:2105-14.

Ballard CG, Margallo-Lana M, Fossey J, et al.2001. A 1-year follow-up study of behavioral and psychological symptoms in dementia among people in care environments. J Clin Psychiatry, 62:631-6.

Boustani M, Peterson B, Hanson L, et al. 2002. Screening for Dementia. Systematic Evidence Review [online]. Accessed on Aug 29, 2008. URL: http://www.ahrq.gov/clinic/uspstfix. Rockville, MD: Agency for Healthcare Research and Quality.

Brodaty H, Draper B, Saab D, et al. 2001. Psychosis, depression, and behavioral disturbances in Sydney nursing home residents: prevalence and predictors. Int J Geriatr Psychiatry, 16:504-12.

Chung JA, Cummings JL. 2000. Neurobehavioral and neuropsychiatric symptoms in Alzheimer's disease: characteristics and treatment. Neurol Clinics, 18:829-46.

Cohen-Mansfield J. 1995. Assessment of disruptive behavior/agitation in the elderly: function, methods, and difficulties. J Geriatr Psychiatry Neurol, 8:52-60.

Colerick EJ, George LK. 1986. Predictors of institutionalization among caregivers of patients with Alzheimer's disease. $J$ Am Geriatr Soc, 34:492-8.

Cummings JL, Donohue JA, Brooks RL. 2000. The relationship between donepezil and behavioral disturbances in patients with Alzheimer's disease. Am J Geriatr Psychiatry, 8:134-40.

Cummings JL, Kaufer D. 1996. Neuropsychiatric aspects of Alzheimer's disease: the cholinergic hypothesis revisited. Neurology, 47:876-83.

Cummings JL, Mega M, Gray K, et al. 1994. The Neuropsychiatric Inventory: comprehensive assessment of psychopathology in dementia. Neurology, 44:2308-14.

Cummings JL, Nadel A, Masterman D, et al. 2001. Efficacy of metrifonate in improving the psychiatric and behavioral disturbances of patients with Alzheimer's disease. J Geriatr Psychiatry Neurol, 14:101-8.

Cummings JL. 2000a. Cholinesterase inhibitors: a new class of psychotropic compounds. Am J Psychiatry, 157:4-15.

Cummings JL. 2000b. Cognitive and behavioral heterogeneity in Alzheimer's disease: seeking the neurobiological basis. Neurobiol Aging, 21:845-61.

Devanand DP, Jacobs DM, Tang MX, et al. 1997. The course of psychopathological features in mild to moderate Alzheimer's disease. Arch Gen Psychiatry, 54:257-63.

Doody RS, Stevens JC, Beck C, et al. 2001. Practice parameter: management of dementia (an evidence-based review). Report of the Quality Standards Subcommittee of the American Academy of Neurology. Neurology, 56:1154-66.

Erkinjuntti T, Kurz A, Gauthier S, et al. 2002. Efficacy of galantamine in probable vascular dementia and Alzheimer's disease combined with cerebrovascular disease: a randomized trial. Lancet, 359:1283-90.

Feldman H, Gauthier S, Hecker J, et al. 2001. A 24-week, randomized, double-blind study of Donepezil in moderate to severe Alzheimer's disease. Neurology, 57:613-20. 
Finkel SI, Burns A, Cohen GD. 2000. Overview. Int Psychogeriatr, 12(Suppl):13-8.

Gauthier S, Feldman H, Hecker J, et al. 2002. Functional, cognitive and behavioral effects of donepezil in patients with moderate Alzheimer's disease. Curr Med Res Opin, 18:347-54.

Green CR, Marin DB, Mohs RC, et al. 1999. The impact of behavioral impairment on functional ability in Alzheimer's disease. Int $J$ Geriatr Psychiatry, 14:307-16.

Hamel M, Gold DP, Andres D, et al. 1990. Predictors and consequences of aggressive behavior by community-based dementia patients. Gerontologist, 30:206-11.

Haupt M, Kurz A, Janner M. 2000. A 2-year follow-up of behavioral and psychological symptoms in Alzheimer's disease. Dement Geriatr Cogn Disord, 11:147-52.

Haupt M, Kurz A. 1993. Predictors of nursing home placement in patients with Alzheimer's disease. Int J Geriatr Psychiatr, 8:741-7.

Holmes C, Wilkinson D, Dean C, et al. 2004. The efficacy of donepezil in the treatment of neuropsychiatric symptoms in Alzheimer disease. Neurologyi, 63:214-9.

Howard RJ, Juszczak E, Ballard CG, et al. 2007. Donepezil for the treatment of agitation in Alzheimer's disease. N Engl J Med, 357:382-92.

Iverson GL, Hopp GA, DeWolfe K, et al. 2002. Measuring change in psychiatric symptoms using the Neuropsychiatric Inventory: Nursing Home version. Int J Geriatr Psychiatry, 17:438-43.

Kaufer DI, Cummings JL, Christine D, et al. 1998. Assessing the impact of neuropsychiatric symptoms in Alzheimer's disease: the Neuropsychiatric Inventory Caregiver Distress Scale. J Am Geriatr Soc, $46: 210-5$.

Kinney JM, Stephens MA. 1989. Caregiving Hassle Scale: assessment the daily hassles of caring for a family member with dementia. Gerontologist, 29:328-32.

Levy ML, Cummings JL, Fairbanks LA, et al.1996. Longitudinal assessment of symptoms of depression, agitation, and psychosis in 181 patients with Alzheimer's disease. Am J Psychiatry, 153:1438-43.

Lyketsos CG, Lopez O, Jones B, et al. 2002. Prevalence of neuropsychiatric symptoms in dementia and mild cognitive impairment: results from the cardiovascular health study. JAMA, 288:1475-83.

Lyketsos CG, Steinberg M, Tschanz JT, et al. 2000. Mental and behavioral disturbances in dementia: findings from the Cache county study on memory in aging. Am J Psychiatry, 157:708-14.

Maslach C, Jackson SE. 1981. The measurement of experienced burnout. J Occup Behav, 2:99-113.

McKeith I, Del Ser T, Spano P, et al. 2002. Efficacy of rivastigmine in dementia with Lewy bodies: a randomized, double-blind, placebo-controlled international study. Lancet, 356:2031-6.

Morris PK, Rovner BW, German PS. 1996. Factors contributing to nursing home admission because of disruptive behavior. Int $J$ Geriatr Psychiatry, 11:243-9.

Mulsant BH, Mazumdar S, Pollock BG, et al. 1997. Methodological issues in characterizing treatment response in demented patients with behavioral disturbances. Int J Geriatr Psychiatry, 12:537-47.

Nunez M, Jakab G, Jakobsen S, et al. 2003. Donepezil-treated Alzheimer's disease patients initially rated as showing 'no apparent clinical benefit' demonstrate significant benefits when therapy is continued [abstract]. AGS Annual Meeting, 2003. S99.
O’Donnell BF, Drachman DA, Barnes HJ, et al. 1992. Incontinence and troublesome behaviors predict institutionalization in dementia. J Geriatr Psychiatry Neurol, 5:45-52.

Rockwood K, Mintzer J, Truyen L, et al. 2001. Effects of a flexible galantamine dose in Alzheimer's disease: a randomized, controlled trial. Neurol Neurosurg Psychiatry, 71:589-95.

Schneider LS, Tariot PN, Lyketsos CG, et al. 2001. National Institute of Mental Health Clinical Antipsychotic Trials of Intervention Effectiveness (CATIE): Alzheimer disease trial methodology. Am J Geriatr Psychiatr, 9:346-60.

Steele C, Rovner B, Chase GA, et al. 1990. Psychiatric symptoms and nursing home placement of patients with Alzheimer's disease. Am J Psychiatry, 147:1049-51.

Steinberg M, Sheppard JM, Tschanz J, et al. 2003. The incidence of mental and behavioral disturbances in dementia: the cache county study. $J$ Neuropsychiatry Clin Neurosci, 15:340-5.

Street JS, Clark WS, Gannon KS, et al. 2000. Olanzapine in the treatment of psychotic and behavioral symptoms in patients with Alzheimer's disease in nursing care facilities: a double-blind, randomized, placebo-controlled trial. The HGEU Study Group. Arch Gen Psychiatry, 57:968-76.

Swearer JM. 1994. Behavioral disturbances in dementia. In: Morris JC (ed). Handbook of Dementing Illnesses. New York: Marcel Dekker, pp. 499-527.

Tariot PN, Blazina L. 1994. The psychopathology of dementia. In: Morris JC (ed). Handbook of Dementing Illnesses. New York: Marcel Dekker, pp. 461-75.

Tariot PN, Cummings JL, Katz IR, et al. 2001. A randomized, double-blind, placebo-controlled study of the efficacy and safety of donepezil in patients with Alzheimer's disease in the nursing home setting. $J \mathrm{Am}$ Geriatr Soc, 49:1590-9.

Tariot PN, Solomon PR, Morris JC, et al. 2000. A 5-month, randomized, placebo-controlled trial of galantamine in AD. The Galantamine USA-10 Study Group. Neurology, 54:2269-76.

Teresi JA, Weiner AS. 1993. Respite care in the nursing home: predictors of length of stay. In: Tepper LM, Toner JA (eds). Respite Care: Programs, Problems and Solutions. Philadelphia: Charles Press, pp. 183-200.

Trinh NH, Hoblyn J, Mohanty S, et al. 2003. Efficacy of cholinesterase inhibitors in the treatment of neuropsychiatric symptoms and functional impairment in Alzheimer's Disease: A meta-analysis. JAMA, 289:210-6.

Wilcock G, Black SE, Hendrix SB et al. 2008. Efficacy and safety of tarenflurbil in mild to moderate Alzheimer's disease: a randomized phase 11 trial. Lancet Neurol, 7:483-93.

Winblad B, Cummings J, Andreasen N, et al. 2007. A six month double-blind, randomized, placebo-controlled study of a transdermal patch in Alzheimer's disease- Rivastigmine patch vs capsule. Int J Geriatr Psychiatry, 22:456-67.

Winblad B, Engedal K, Soininen H, et al. 2001. A 1-year, randomized, placebo-controlled study of donepezil in patients with mild to moderate AD. Neurology, 57:489-95.

Winblad B, Kilander L, Eriksson S, et al. 2006. Donepezil in patients with severe Alzheimer's disease: double blind, parallel-group, placebo-controlled study. Lancet, 367:1057-65.

Wood S, Cummings JL, Hsu MA, et al. 2000. The use of the neuropsychiatric inventory in nursing home residents: characterization and measurement. Am J Geriatr Psychiatry, 8:75-83. 


\section{Flow chart}

Potentially relevant RCTs identified and screened for retrieval: $\mathrm{N}=105$

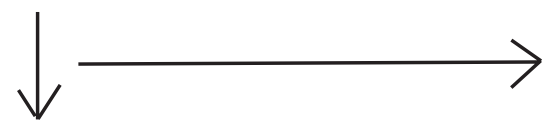

RCTs excluded:

$\mathrm{N}=16$

Not placebo-controlled trials

RCTs retrieved for more detailed evaluation

$(n=89)$

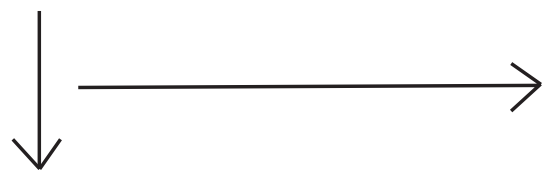

RCTs excluded, with reasons

$(n=27)$

Open label $=17$

Sub-group analyses $=3$

Duplicate $=7$

Potentially appropriate RCTs to be included in the meta-analyses $(n=62)$

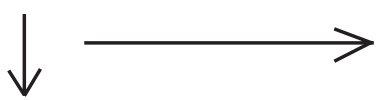

RCTs excluded from the meta-analysis: $(\mathrm{n}=50)$

Failed to meet inclusion criteria

RCTs included in meta-analysis:

$(n=12)$

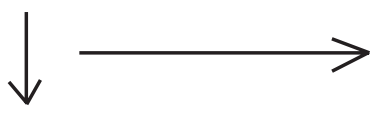

RCTs withdrawn by outcome

$(n=3)$

Reasons: Data not reported

RCTs with usable information by outcome

$(n=9)$

Abbreviations: RCTs, randomized, controlled trials. 